\title{
DESENVOLVIMENTO SUSTENTÁVEL, DESENVOLVIMENTO COMO LIBERDADE E A CONSTRUÇÃO DA CIDADANIA NA PERSPECTIVA AMBIENTAL
}

\author{
Jean de Sousa Jardim
}

\section{RESUMO}

No contexto moderno, pensar o desenvolvimento sustentável é analisar a relação entre desenvolvimento econômico e meio ambiente e buscar mecanismos de equilíbrio entre ambos para que o homem, com liberdades mínimas, isto é, com condições suficientes para sobrevivência, construa a sua autonomia, sua cidadania e sua liberdade frente ao desenvolvimento econômico sem desprezo ao meio ambiente e identificar, na ecologia de restauração, a fundamentação cidadã do desenvolvimento sustentável.

Palavras-chaves: desenvolvimento sustentável; liberdade; cidadania e meio ambiente

\begin{abstract}
To think of sustainable development, in a modern context, is to analyze the relationship between the economic development and the environment and look for balancing mechanisms between them, so that men, beginning from minimal freedoms or adequate conditions for survival, may build their autonomy, citizenship and freedom in light of the economic development but with respect to the environment, seeking in the restoration ecology the civic foundation for sustainable development.
\end{abstract}

Keywords: sustainable development; freedom; citizenship and environment 


\section{Introdução}

O desenvolvimento sustentável é o discurso aberto frente à necessária busca de equilíbrio entre o desenvolvimento econômico e o meio ambiente. Entretanto, percebe-se que a independência entre ambos é transparente. Nessa construção sustentável, a mobilização social mundial é a primeira trilha a ser desvendada pelo homem que percebeu a degradação como efeito de suas ações. Isto significa a possibilidade de tomada de postura na concretização de alianças gravitacionais no eixo de consenso mínimo sobre a relação entre o homem e o meio ambiente.

A Conferência ápice destas questões foi a das Nações Unidas sobre o Meio Ambiente e Desenvolvimento (ECO-92), que colocou, no âmago das discussões, o combate à pobreza, pois a sua relação com a degradação é íntima, e seu combate, necessário, isto é, trazê-la ao ponto mínimo permite que o indivíduo se desenvolva como cidadão, em pugna constante com segmentos sociais no exercício da cidadania ambiental. Tal necessidade é a bandeira do desenvolvimento como liberdade proposta por Amartya Sen, na idéia das liberdades subjetivas em que o indivíduo necessita estar servido pelas mínimas condições de sobrevivência para ser um cidadão ambiental.

A inquietude por um meio ambiente saudável deve incorporar-se à significação de manutenção e conservação dos recursos naturais, muito embora sejam necessários avanços tecnológicos e científicos para capacitar a sociedade na busca pela qualidade de vida eficiente, pelo desenvolvimento sustentável eficaz, pela dignidade da pessoa humana no exercício da cidadania ambiental constante e na preservação de princípios ambientais coerentes. 


\section{Sustentabilidade: desenvolvimento e preservação}

Ao tratar de sustentabilidade e desenvolvimento sustentável ${ }^{2}$, remetemo-nos ao impasse inevitável: como estabelecer equilíbrio entre o desenvolvimento econômico ${ }^{3}$, científico e tecnológico e a preservação ambiental? Talvez, a velha máxima de que os recursos ambientais não são esgotáveis tenha-se distanciado da atividade econômica, conduzindo-a à realidade com mais preocupação na idéia de conciliação do desenvolvimento frente à preservação do meio ambiente e a melhoria da qualidade de vida ${ }^{4}$. De certa feita, surgiu a necessidade de desenvolver políticas de sustentação racional de recursos naturais, levando ao desenvolvimento econômico motivado pela transformação sociopolítica, tecnológica, legislativa, teórica, a buscar o equilíbrio sustentável no modelo de Estado intervencionista. Por isso, a base conceitual do novo paradigma, o do desenvolvimento sustentável ${ }^{5}$, em várias definições, representa a mobilização

\footnotetext{
${ }^{2}$ O desenvolvimento sustentável faz emergir a cidadania ambiental, que elastece a idéia dos direitos humanos, principalmente no tinente à igualdade, pois desenha, no cidadão, a silhueta sadia de ser humano e semeia às futuras gerações a real eqüidade intergeracional na garantia do meio ambiente latente a verdadeiro desenvolvimento que se sustenta.

${ }_{3}^{3}$ Devem-se creditar ao desenvolvimento econômico a expectativa de justificativa social e a proteção aos recursos naturais.

${ }^{4}$ Nisto, podemos tirar lições da Constituição da República Federativa do Brasil de 1998, no artigo 225, capítulo VI: "Todos têm o direito ao meio ambiente ecologicamente equilibrado, bem de uso comum do povo e essencial à sadia qualidade de vida, impondo-se ao Poder Público e à coletividade o dever de defendê-lo e preservá-lo para as presentes e futuras gerações. \& $1^{\circ}$. Para assegurar a efetividade desse direito, incumbe ao Poder Público: I- preservar e restaurar os processos ecológicos essenciais e promover o manejo ecológico das espécies e ecossistemas; IIpreservar a diversidade e a integridade do patrimônio genético do País e fiscalizar as entidades dedicadas à pesquisa e manipulação de material genético; VI- promover a educação ambiental em todos os níveis de ensino e a conscientização pública para a presevarção do meio ambiente”.

${ }^{5}$ Sobre o desenvolvimento sustentável, vale lembrar a sua expansão no direito internacional citado no dizer do Professor Marcelo Dias Varella: “A expansão do direito internacional do meio ambiente se opera em dois planos: a elaboração de disposições sobre a proteção da natureza e o seu acompanhamento pelas normas para a proteção do desenvolvimento, característica da fusão entre o direito do desenvolvimento com o direito internacional do meio ambiente, que se opera a partir dos anos 70 [...] Os dois conjuntos de regras são a priori inseparáveis, mas de fato separados, o que permite separar as normas sobre o desenvolvimento das normas sobre a proteção da natureza. O direito internacional do meio ambiente foi edificado sobre a base da redução da pobreza, a partir da consideração de que não seria possível impor o respeito à natureza, pelos países do Sul, sem que este respeito fosse acompanhado pela proteção do desenvolvimento, nem a adoção de um controle mais eficaz sobre os níveis de consumo" (VARELLA, Marcelo Dias. Direito internacional econômico ambiental. Belo Horizonte: Del Rey, 2003. p. 51-52) 
social $^{6}$ na questão ambiental em primeiro plano, na agenda política internacional. Assim, no dizer de Fiorillo:

\begin{abstract}
“O princípio do desenvolvimento sustentável tem por conteúdo a manutenção das bases vitais da produção e reprodução do homem e de suas atividades, garantindo igualmente uma relação substancial entre os homens e destes com o seu ambiente, para que as futuras gerações também tenham oportunidade de desfrutar dos mesmos recursos que temos hoje à nossa disposição.” 7
\end{abstract}

Percorre-se a idéia de que o "desenvolvimento sustentável consiste no progresso da atividade econômica compatível com a utilização racional dos recursos ambientais. Representando a rejeição do desperdício, da ineficiência e do desprezo por esses recursos” ${ }^{8}$. A problemática ambiental revela junções de alianças. Por esse refletir, Marcos Nobre dá-nos um significado justo:

"Desenvolvimento sustentável significa, de um lado, a concretização de alianças em termo de um consenso mínimo a respeito da problemática ambiental, e, de outro, a arguta tentativa de aproveitar um ambiente mundial de relativa distenção e de intensa mobilização social em torno das questões ecológicas, para levar a questão ambiental para o primeiro plano da agenda política internacional”. ${ }^{9}$

É inevitável associar a idéia de sustentabilidade ao significado de manutenção e conservação “ab aeterno” dos meios ambientais. “ Isso exige avanços científicos e tecnológicos que ampliem permanentemente a capacidade de utilizar, recuperar e conservar esses recursos, bem como novos conceitos de necessidades humanas para aliviar a pressão da sociedade sobre eles” ${ }^{10}$ e o interesse tanto público como privado pela satisfação das necessidades humanas sem o

\footnotetext{
${ }_{7}^{6}$ A principal luta da cidadania é a concretização da liberdade, e ela faz-se pela ecocidadania.

7 FIORILLO, Celso Antônio Pacheco e DIAFÉRIA, Adriana. Biodiversidade e patrimônio genético no Direito Ambiental brasileiro. São Paulo: Max Limonad, 1999. p. 31.

${ }^{8}$ OLIVEIRA, José Marcos Domingues de. Direito Tributário e meio ambiente: proporcionalidade, tipicidade aberta, afetação da receita. Rio de Janeiro: Renovar, 1995. p. 12.

${ }^{9}$ NOBRE, Marcos. Desenvolvimento sustentado e problemática ambiental. Lua Nova: São Paulo. n. 47, 1999.

${ }^{10}$ BARBIERI, José Carlos. Desenvolvimento e meio ambiente: as estratégias de mudança da Agenda 21. 3. ed. Petrópolis: Vozes, 2000. p. 31. 
desprezo por parte do desenvolvimento econômico ${ }^{11}$ ao desenvolvimento sustentável, isto é, o descortinar do fim ao caos ambiental que se instalou na senda moderna pelo desenvolvimento como término das privações e construidor e manentedor das condições essenciais para o real envolvimento do ser humano por meio da igualdade e da liberdade frente à cidadania ambiental.

\section{A perspectiva da liberdade}

O homem só é valor porque, antes, é pessoa, sujeito moral com fim em si mesmo. Só é pessoa porque a sua essência agasalha-se no espírito e está no pensamento, onde a característica maior é ser livre. Sendo livre, autônomo, constitui-se não apenas como valor relativo mas também como valor intrínseco a sua dignidade. Basta em si mesmo, pois está no princípio do pensamento, no princípio do espírito. "Meu espírito, isto é, eu mesmo enquanto sou apenas uma coisa que pensa” ${ }^{12}$; total oposição à matéria e ao testemunho pleno da liberdade reflexiva do homem.

Segundo Locke, nos fundamentos de um governo político: “A liberdade é o fundamento de tudo quanto o homem pode ter na terra, é o primeiro dos bens civis do cidadão”. Entretanto, esse bem só pode ser e existir na comunidade de videntes, na troca com o outro. Não se pode conceber liberdade humana como ser “ilha”, pois nascemos uns para os outros na relação de necessidade intersubjetiva, em que o outro não é o limite de liberdade, mas a porta da

\footnotetext{
${ }^{11}$ A relação feita por Marcelo Varella entre o binômio meio ambiente e crescimento econômico expressa a variação conceitual da idéia de desenvolvimento no direito internacional. Seu dizer é: "A utilização de um conteúdo determinado tem relação direta com a lógica trabalhada em cada instituição. Na lógica liberal, o desenvolvimento é sobretudo ligado ao volume de trocas e ao crescimento do Produto Nacional Bruto. Quanto mais existe comércio ou mais o PIB aumenta, mais há desenvolvimento. Em uma lógica mais política e social, o desenvolvimento é medido pela expansão de liberdades, como acesso à saúde e à educação, à proteção do meio ambiente e à democracia". (VARELLA, Marcelo Dias. Direito internacional econômico ambiental. Belo Horizonte: Del Rey, 2003.p. 40)

12 Confira mais nas “Respostas às quintas objeções”, In: Descartes, Oeuvres, Lettres, La Plêiade, Gallimard. p.482 
liberdade. Já em outra definição, de Meleau-Ponty, a liberdade só se realiza na capacidade de assumirmos nossa situação natural e social:

"O que é então a liberdade? Nascer é ao mesmo tempo nascer do mundo e nascer no mundo. O mundo está já constituído, mas também não está nunca completamente constituído. Sob o primeiro aspecto, somos solicitados, sob o segundo, somos abertos a uma infinidade de possibilidades. Mas esta análise ainda é abstrata, pois existimos sob os dois aspectos ao mesmo tempo. Portanto, nunca há determinismo ${ }^{13}$ e nunca há escolha absoluta, nunca sou coisa e nunca sou consciência nua. Em particular, mesmo nossas iniciativas, mesmo as situações que escolhemos uma vez assumidas, nos conduzem como que por benevolência. A generalidade do' papel' e da situação vem em auxílio da decisão e, nesta troca entre a situação e aquela que assume, é impossível delimitar a 'parte da situação'e a 'parte da liberdade’”. ${ }^{14}$

Nessa relação de troca, escolhemos e somos escolhidos pelas coisas e pelo mundo. Só é possível vivermos uma liberdade condicional na cooperação, na reciprocidade, no compromisso. Pois, incondicionalmente, a liberdade está fincada na transcendência do espírito. Por isso, o caminho da liberdade, tal qual o da democracia, só se faz pelo da igualdade, pelo desacorrentar dos espíritos ante o alcance do outro como seu semelhante. É o apagar dos limites doentios do individualismo, o estancar da “meia -liberdade”, da “meia-igualdade jurídica” para que, do outro lado da cortina, as mãos enganadoras não nos tape os olhos e fira o coração ${ }^{15}$.

Por tudo e mais, o caminho da liberdade passa pela tolerância rumo à verdade de cada homem. Só assim, será possível ser livre e expressar-se na melhoria da sorte humana à senda constante da verdade, cujo fim é a liberdade. No dizer de Herbert Marcuse: “a verdade é o fim da liberdade” e deve a liberdade definir-se e limitar-se sempre por ela: a verdade. Nesse

${ }^{13}$ Acho prudente conceituar determinismo para dirimirmos confusões. Determinismo, segundo RUSS, Jaqueline. Dictionnaire de Philosophie. Bordas: Paris, 1991. p.65, é: “(s.m.) Etim.: lat. Determinare, fixar ou marcar os limites, delimitar. A. Epistemologia, ciência: a) conjunto das condições necessárias para que um fenômeno dado se produza (ex.: conhecer o determinismo de um eclipse); b) doutrina, concepção segundo a qual, sendo dadas e conhecidas certas condições, os fatos que se seguirão a elas são previsíveis com precisão. B. Metafísica: doutrina filosófica que coloca que a necessidade reina no universo".

${ }^{14}$ MERLEAU-PONTY, Maurice. Fenomenologia da percepção. São Paulo, Martins Fontes, 1999.

${ }^{15}$ MIRANDA,Pontes de. Democracia, liberdade e igualdade. Campinas: Bookseller,2002. 
ínterim, voz forte a favor da liberdade é, sem embargos, a democracia. É com ela que a liberdade de comportamento se desenha, descobre-se e constrói-se.

Na estrutura moderna, é impossível dissociar a idéia de liberdade no mundo imaterial da idéia de liberdade no mundo material, muito embora, a do mundo material seja a que, vez em sempre, dita a caminhada. Por isso, há "relação entre vendas e realizações, entre mercadorias e capacidades, entre nossa riqueza econômica e nossa possibilidade de viver do modo como gostaríamos” 16

Daí perceber que a ponte entre o mundo imaterial (liberdade transcendental, satisfação metafísica) e o mundo material (atenção exclusiva na riqueza econômica) é a essência discursiva do desenvolvimento, pois permite maior liberdade na escolha de vida com qualidade. A razão a estabelecer é que a visão de desenvolvimento deve transcender a acumulação material, isto é, o desenvolvimento está na possibilidade que nos permite fazer nas liberdades subjetivas ${ }^{17}$ que podemos obter. No dizer de Amantya Sen:

"Uma concepção adequada de desenvolvimento deve ir muito além da acumulação de riqueza e do crescimento do Produto Nacional Bruto e de outras variáveis relacionadas à renda. Sem desconsiderar a importância do crescimento econômico, precisamos enxergar muito além dele" ${ }^{18}$

Não obstante, deve-se considerar que o desenvolvimento econômico não pode ser o fim em si mesmo. É impossível desfrutar a liberdade, tendo qualquer privação. Toda forma de privação de liberdade é a negação da liberdade de sobreviver. É a concepção de desigualdade

\footnotetext{
16، As liberdades subjetivas incluem capacidades elementares como, por exemplo, ter condições de evitar privações como a fome, a subnutrição, a morbidez evitável e a morte prematura, bem como as liberdades associadas ao saber ler e fazer cálculos aritméticos. Ter participação política e liberdade de expressão etc. Nessa perspectiva constitutiva, o desenvolvimento envolve a expansão dessas e de outras liberdades básicas. É o processo de expansão das liberdades humanas, e sua avaliação tem que basear-se nessa consideração.” (SEN, Amartya. 2000, p. 52)

${ }^{17}$ SEN, Amartya Kumar. Desenvolvimento como liberdade. Trad. Laura Teixeira Mota. São Paulo: Cia. das Letras, 2000, p. 27.

${ }^{18}$ Idem, p. 28.
}

Revista do Programa de Mestrado em Direito do UniCEUB, Brasília, v. 2, n. 1, p. 189-201, jan./jun. 2005 
de oportunidade na ausência de condições mínimas de existência (tais como, o acesso a saúde, saneamento básico, educação funcional, emprego remunerado) que isola e nega a "condição de agentes” ${ }^{19}$ impossibilitando-os de atuar livremente e de construir o futuro como queiram, ou seja, na transcendência de si mesmo.

Continuando com a lógica da liberdade do indivíduo de acordo com a visão de Amantya Sen, concluímos que a chave para o desenvolvimento é a mínima da existência do homem, isto é, livrando-o da fome, permitindo-lhe condições de saúde, educação e trabalho para a promoção das pessoas em agentes, garantindo as engrenagens do caminhar ao desenvolvimento.

"O desenvolvimento consiste na diminuição de privações de liberdade eu limitam as escolhas e as oportunidades das pessoas de exercer ponderadamente sua condição de agente. A eliminação de privações de liberdades substanciais argumentasse aqui, é constitutiva do desenvolvimento.” 20

Portanto:

“Com oportunidades sociais adequadas, os indivíduos podem efetivamente moldar o seu próprio destino e ajudar uns aos outros. Não precisam ser vistos, sobretudo como beneficiários passivos de engenhosos programas de desenvolvimento. Existe, de fato, uma sólida, base racional para reconhecermos o papel positivo da condição de agente livre e sustentável...”21

À guisa de conclusão, Sen declara que:

“O processo de desenvolvimento, nessa visão, não difere em essência da história do triunfo sobre essas privações de liberdade. Embora essa história não seja de modo algum desvinculada do processo de crescimento econômico e de acumulação de capital físico e humano, seu alcance e abrangência vão muito além dessas variáveis.” 22

\section{Desenvolvimento como liberdade}

${ }^{19}$ Idem. p. 10.
${ }^{20}$ Idem, p. 10.
${ }^{21}$ Idem, p. 26.
${ }^{22}$ Idem. p. 49. 
Segundo Sen "quanto mais incluso for o alcance da educação básica e dos serviços de saúde, maior será a probabilidade de que mesmo os potencialmente pobres tenham uma chance de superar a penúria” ${ }^{23}$. Isso nos faz pensar que, quanto mais oportunidades na quebra do “acoplamento de desvantagens” o indivíduo possuir, mais desenvolvimento e menos privação de liberdade vai enfrentar. Tal mínimo (as liberdades substanciais básicas) torna o indivíduo mais suscetível a liberdade, transformando a sociedade, melhorando a economia e garantindo o livre mercado. Então, desenvolver ${ }^{24}$ é dar condições substanciais de liberdade, e a garantia substantiva deve ser fornecida pelo Estado. Para isso, Sen vê com grande importância “as liberdades substantivas - as capacidades - de escolher uma vida que se tem razão para valorizar." 25

Assim, o indivíduo poderá escolher, distante das privações, outras possibilidades. Nesse caso, “a noção de liberdade como poder efetivo para realizar o que se escolherá é uma parte importante da idéia geral de liberdade.” ${ }^{26}$ Definimos por meio de Sen que o desenvolvimento é a ampliação das liberdades positivas. Para Ignacy Sachs, desenvolvimento é a efetivação dos direitos humanos em várias trilhas rumo à libertação passando pela “visão do ser na partilha justa do ter” ${ }^{27}$, ou seja:

“O desenvolvimento é, portanto, um processo, o qual pode ser descrito como libertação. Não só em termos metafóricos, pois o desenvolvimento passa pela libertação da fome, da miséria da ociosidade forçada dos desempregados.

\footnotetext{
${ }^{23}$ Idem. p. 113.

24 “A proteção do meio ambiente tornou-se elemento fundamental desde o processo de desenvolvimento. Considerase que toda forma de crescimento não-sustentável contribui para a redução das liberdades das gerações futuras e, portanto, é naturalmente proposto ao conceito de desenvolvimento, que prevê a expansão destas liberdades. Segundo o conceito, não pode haver desenvolvimento que seja não-sustentável e, assim, nenhuma forma de crescimento nãosustentável pode ser considerada desenvolvimento"(VARELLA, Marcelo Dias. Direito internacional econômico ambiental. Belo Horizonte: Del Rey, 2003.p. 43)

${ }^{25}$ SEN, Amartya Kumar. Desenvolvimento como liberdade. Trad. Laura Teixeira Mota. São Paulo: Cia. das Letras, 2000, p. 94.

${ }^{26}$ SEN, Amartya. Desigualdade reexaminada. Record: Rio de Janeiro, 2001. p. 118.

27 Definição trazida pelo dominicano francês Joseph Lebret e aceita por Ignacy Sachs, quando dito por Lebret: “d’une civilisation de L’ être dans le portage de l’avair”, isto é, de uma civilização do ser na partilha justa do ter. 
Libertação também porque, etimologicamente, a palavra desenvolver significa tirar a casca do grão, dar a possibilidade de crescer, remover os obstáculos ao desenvolvimento. O processo da remoção dos obstáculos e da ampliação e efetivação dos direitos humanos passa por várias fases: aspirações, reivindicações, lutas, reconhecimento do direito.” 28

\section{A ecologia da restauração na construção da cidadania}

Ser cidadão envolve posturas públicas, sociais e econômicas. O ambientalismo

é uma das posturas que se associam à luta pela cidadania, pois propõe forma equilibrada de apropriação dos recursos naturais que passa a ser chamada de exercício da cidadania ambiental.

Na linguagem de Walter V.C. Reid, membro do Instituto de Recursos Mundiais

e especialista em pesquisas sobre política, relativas à conservação dos recursos biológicos:

"Um instrumento que tornará cada vez mais importante na manutenção da diversidade biológica no mundo e no equilíbrio do desenvolvimento com a integridade do meio ambiente é a ecologia de restauração. À medida que o crescimento demográfico se desacelera e à medida que amadurecem os políticos e as instituições para a administração de recursos comuns, crescem as oportunidades de sustentação de ecossistemas altamente degradados com sua transformação em algo que se aproxime de seu estado natural....Um exemplo pioneiro de potencial da ecologia de restauração [...] é a integração da floresta tropical seca (Parque Nacional Guanacaste, em Costa Rica) com as necessidades do povo local. O Parque beneficiará os residentes nas proximidades através de proteção da bacia, da receita do turismo e da disponibilidade de empregos. Além do mais, como programa educacionais resultados voltados para os escolares, grupos cívicos e turistas, o Parque ganhará com o aumento da consciência local da importância da conservação; enquanto o povo adquirirá melhor compreensão de seu meio ambiente"29.

É mensurável que o estabelecimento de relações sociais cidadãs favoreçam a diminuição das desigualdades sociais gerando nova ética de comportamento, a ética ambiental, que conduz ao exercício da cidadania ambiental, cuja construção é elemento essencial na

${ }^{28}$ SACHS, Ignacy. Desenvolvimento e Direitos Humanos; (conferência na Universidade Federal de Alagoas); saudações de Rodrigo Ramalho Filho e Vinícius Nobre Lage. Maceió: Prodema, 2000, p. 32.

${ }^{29}$ REID, Walter V. C. Desenvolvimento sustentável: lições do êxito. Economic Impact, São Paulo. abril/jun, n. 71, 2000. p. 30. 
formação cultural do indivíduo que se edifica na via da preservação da memória individual e coletiva pela preocupação da manutenção do meio ambiente como estratégia do desenvolvimento sustentável, pois o equilíbrio entre capital e meio ambiente deve estar intimamente ligado a elementos que assegurem a construção e o exercício do ser cidadão e da liberdade real e não o de uma liberdade mínima, impossibilitado pelas privações.

\section{Conclusão}

O desenvolvimento sustentável é a equação que deve ter, como alicerce, a preservação do meio ambiente e, como pilar, o desenvolvimento econômico, na tentativa de buscar satisfazer a melhor relação entre progresso, meio e homem. Traduz-se, ademais, em harmonia na convergência do desenvolvimento científico, tecnológico, cultural para que o homem alcance a dimensão das liberdades, isto é, a liberdade material e a imaterial. Também, no novo conceito, o da cidadania ambiental ou ecocidadania, o ser humano deve ser o elo importante da coesão social para a real medida ${ }^{30}$ do desenvolvimento da cidadania em todas as possibilidades, para que o indivíduo saia da qualidade de objeto de e para o poder à qualidade de sujeito capaz de redimensionar a idéia de existência na obtenção do título de cidadão planetário e da autonomia consistente, sem a negação da subjetividade. Por isso, bem declara Francisco Garrido Peña:

\footnotetext{
${ }^{30}$ A medida do desenvolvimento tem de aglutinar meios para a não-desvalorização da esperança de vida e harmonia entre o homem, o progresso e o meio. No dizer de Varella: "A medida do desenvolvimento pode ser realizada de diversas formas, conforme diferentes critérios. A adoção de um critério por um ator internacional demonstra o que ele valoriza mais. Se ele toma como indicador de desenvolvimento o Produto Nacional Bruto ou o Produto Nacional Bruto por Habitante, como faz o Fundo Monetário Internacional, significa que a economia é o elemento mais valorizado, e não necessariamente a educação, a esperança de vida, o meio ambiente, por esses índices não serem, de forma alguma, diretamente proporcionais a estes outros elementos. O volume do comércio é também freqüentemente utilizado como índice de desenvolvimento: é o critério que emprega, por exemplo, a Organização Mundial do Comércio. Embora possa haver relação entre os elementos indicados”. (VARELLA, Marcelo Dias. Direito internacional econômico ambiental. Belo Horizonte: Del Rey, 2003.p. 43) 
"La conquista de la autonomía nada tiene que ver con la destrucción de la subjetividad que propone el totalitarismo colectivista que hace del todo la una nueva hipótesis monista; ni el autismo individualista que destruye los vínculos sociales y temporales donde nace y se hace posible toda singularidad individual. [...] La moderna definición de la ciudadanía, con su continua ampliación de universo, ha devenido en una definición inflacionaria que destruye en su crecimiento el valor de lo que crece sin medida. El molde del sujeto libre ( ciudadano) que fue construido para el sujeto propietario, varón, occidental, racional se ha extendido a las mujeres, a los asalariados, a los salvajes, a los niños, a los incapacitados. En esa extensión la libertad que define al ciudadano frente al súbdito( ciudadano es el hombre libre)...”31

O declinado esforço é apenas a significação da longa caminhada na inesgotável questão que envolve o tripé da sociedade (progresso-homem-meio) na justa necessidade de

fortalecer o movimento ambientalista como ação primordial do pleno exercício do direito da sadia qualidade de vida em um direito ao meio ambiente ecologicamente equilibrado e do fim da lógica da morte para o brotar da racionalidade de vida na liberdade adjetiva ${ }^{32}$.

\section{Referências}

BARBIERI, José Carlos. Desenvolvimento e meio ambiente: as estratégias de mudança da agenda 21, 3. ed. Petrópolis: Vozes, 2000.

FIORILLO, Celso Antônio Pacheco; DIAFÊRIA, Adriana. Biodiversidade e patrimônio genético no direito ambiental brasileiro. São Paulo: Max Limonad, 1999.

MERLEAU-PONTY, Maurice. Fenomenologia da percepção. São Paulo: M. Fontes, 1999.

MIRANDA, Pontes de. Democracia, liberdade e igualdade. Campinas: Bookseller, 2002.

NOBRE, Marcos. Desenvolvimento sustentado e problemática ambiental. Lua Nova, São Paulo, n. 47, 1999.

31 PEÑA,Francisco Garrido. De como la ecología política redefine conceptos centrales de la ontología jurídica tradicional: libertad y propriedad. In: VARELLA, Marcelo Dias, BORGES, Roxana Cardozo B. O novo Direito Ambiental. Del Rey, 1998. p. 218.

${ }^{32}$ A idéia de liberdade adjetiva

Revista do Programa de Mestrado em Direito do UniCEUB, Brasília, v. 2, n. 1, p. 189-201, jan./jun. 2005 
OLIVEIRA, José Marcos Domingues de. Direito tributário e meio ambiente:

proporcionalidade, tipicidade aberta, afetação da receita. Rio de Janeiro: Renovar, 1995.

PEÑA, Francisco Garrido. De como la ecología política redefine conceptos centrales de la ontología jurídica tradicional: libertad y propiedad. In: VARELLA, Marcelo Dias; BORGES, Rozana Cardozo B. O novo direito ambiental. Belo Horizonte: Del Rey, 1998.

REID, Walter V. C. Desenvolvimento sustentável: lições do êxito. Economic Impact, São Paulo, n. 71, abr./jun. 2000.

RUSS, Jacqueline. Dictionnarie de philosophie. Paris: Bordas,1991.

SACHS, Ignacy. Desenvolvimento e direitos humanos. Maceió: Prodema, 2000. Conferência magistral ao receber título de doutor honoris causae na Universidade Federal de Alagoas.

Saudações de Rodrigo Ramalho Filho e Vinícius Nobre Lage.

SEN, Amartya. Desenvolvimento como liberdade. São Paulo: Cia. das Letras, 2000.

Desigualdade reexaminada. Rio de Janeiro: Record, 2001.

VARELLA,Marcelo Dias. Direito internacional econômico ambiental. Belo Horizonte: Del Rey, 2003. 